\title{
KIT and PDGFRA mutations and PDGFRA immunostaining in gastrointestinal stromal tumors
}

\author{
ANTONELLA BARRECA ${ }^{1}$, ALESSANDRO FORNARI ${ }^{1}$, LISA BONELLO $^{2}$, FABRIZIO TONDAT $^{2}$, \\ LUIGI CHIUSA ${ }^{1}$, PATRIZIA LISTA ${ }^{3}$ and ACHILLE PICH ${ }^{1}$ \\ ${ }^{1}$ Department of Biomedical Sciences and Human Oncology, Section of Pathology, \\ University of Turin; ${ }^{2}$ Center for Experimental Research and Medical Studies (CERMS); \\ ${ }^{3}$ Division of Medical Oncology, A.O.U. San Giovanni Battista, Turin, Italy
}

Received July 8, 2010; Accepted October 11, 2010

DOI: $10.3892 / \mathrm{mmr} .2010 .399$

\begin{abstract}
In the present study, we investigated the association of PDGFRA and KIT mutations as well as PDGFRA immunohistochemical expression with clinicopathologic features and prognosis in a series of gastrointestinal stromal tumors (GISTs). Tumor DNA from 40 GISTs was sequenced for the presence of mutations in KIT exons 9, 11, 13 and 17, and in PDGFRA exons 12 and 18. Tissue sections were stained with polyclonal anti-PDGFRA antibody. KIT mutations occurred in 26 cases. There were 13 deletions, 6 substitutions, 3 deletionsubstitutions, 3 duplications and 1 insertion. Tumors with KIT deletions/insertion were large with a high mitotic index (MI), and were associated with a high rate of symptoms at diagnosis, invasion into adjacent organs, distant metastasis, relapse and a short disease-free survival (DFS). PDGFRA mutations occurred in 6 gastric GISTs. There were 4 deletions and 2 substitutions. Tumors with PDGFRA mutations were small, with a low MI and Ki67 score, and were associated with a very low rate of symptoms at diagnosis, invasion into adjacent organs and distant metastasis. PDGFRA immunopositivity was found in 23 cases: a peculiar 'dotlike' staining was found in 5 out of 6 PDGFRA mutated cases. Patients with positive PDGFRA immunostaining had a longer DFS than those with negative staining. Our data confirm that the type of KIT mutation is associated with various clinicopathologic features of GISTs, and indicate that PDGFRA mutations are associated with rather indolent tumors. PDGFRA immunopositivity reflects $P D G F R A$ mutational status and is associated with a favorable outcome.
\end{abstract}

Correspondence to: Professor Achille Pich, Department of Biomedical Sciences and Human Oncology, Section of Pathology, University of Turin, Via Santena 7, I-10126 Torino, Italy

E-mail: achille.pich@unito.it

Key words: gastrointestinal stromal tumors, KIT and plateletderived growth factor receptor- $\alpha$ (PDGFRA) mutations, PDGFRA immunohistochemistry, PDGFRA 'dotlike' decoration, prognosis

\section{Introduction}

Gastrointestinal stromal tumors (GISTs) are the most common mesenchymal tumors of the gastrointestinal tract. Most GISTs show KIT or platelet-derived growth factor receptor- $\alpha$ (PDGFRA) gain-of-function mutations (oncogenic mutations) (1-4). Several studies have shown that the type of KIT mutation may be correlated with the clinical outcome of patients with GIST. A poor prognosis and metastatic behavior were found for GISTs with KIT deletions $(5-13)$ or insertions $(5,11,13)$. By contrast, a better prognosis was found for GISTs with KIT substitutions (point mutations) (5,10-12), deletion-substitutions or duplications $(12,14)$. However, conflicting results have been reported (15-19).

Little is known about PDGFRA mutations. In general, PDGFRA mutated cases have a low mitotic rate and good prognosis, and most are gastric GISTs $(4,20)$. While CD117 expression is considered a sensitive marker for KIT activation, there is no consensus concerning the reliability of PDGFRA antibody as a marker (21). However, PDGFRA expression has been detected by immunohistochemistry in a number of tumors, and these results have been confirmed by immunoprecipitation/Western blotting experiments $(22,23)$. Notably, a strong PDGFRA immunoreactivity with prominent perinuclear 'dotlike' accentuation (so-called Golgi pattern) has been reported to be closely associated with PDGFRA mutations $(24,25)$, and was recently found in $70.3 \%$ of PDGFRA mutated cases (26).

The life expectancy of metastatic GIST patients has dramatically changed due to the development of target-based molecular therapy with imatinib mesylate and other tyrosine kinase inhibitors. The determination of clinicopathological and molecular factors predictive of aggressive behavior is therefore of key importance.

In the present study, we analyzed PDGFRA and KIT mutations as well as PDGFRA immunohistochemical expression in 40 patients with GIST in order to investigate the association of the type of mutation and PDGFRA immunostaining with clinicopathologic features and disease prognosis.

\section{Materials and methods}

Patients and treatment. A total of 40 adult patients with newly diagnosed GISTs, admitted to the Division of Surgical 
Oncology, A.O.U. San Giovanni Battista, Turin, Italy, from 1996 to 2006, were included in the study. There were 19 females and 21 males; the mean age was 64.3 years (range 19-84). Diagnosis was established according to the criteria of the 2004 GIST consensus conference (27). Twenty-nine tumors were located in the stomach, 9 in the small bowel and 2 in the large bowel. The mean size of the tumors was $6.3 \mathrm{~cm}$ (range 1-25). According to Fletcher et al (28), the tumors were classified based on the risk of aggressive behavior: 4 were very low risk, 8 low risk, 11 intermediate risk and 17 high risk. GISTs were subtyped into three histopathologic categories: spindle cell, epithelioid or mixed type (28).

After providing their informed consent, the patients underwent surgical resection (5 complete radical, 32 limited complete and 3 incomplete); 8 also received imatinib mesylate. Metastases were present at diagnosis in 3 cases. The follow-up was completed on June 30, 2008. The mean follow-up for the whole series was 39.6 months (range 2-99). Ten (25\%) patients relapsed; 5 (12.5\%) succumbed to the disease. Only the disease-free survival (DFS) was considered in the analysis.

Immunohistochemistry. Immunohistochemistry was performed on 3- $\mu$ m-thick dewaxed sections using the Labeled Streptavidin-Biotin 2 System detection kit (Dako, Glostrup, Denmark), diaminobenzidine as chromogen and the monoclonal antibodies anti CD34 (Clone QBEnd/10; Neomarkers, Freemont, CA, USA), dilution 1:50; Smooth Muscle Actin (Clone1A4; Dako), dilution 1:50; Vimentin (CloneV9; Dako), dilution 1:100; Desmin (Clone D33; Dako), dilution 1:50; CD44 (clone DF1485; Dako), dilution 1:30; Ki-67 Antigen (Clone MIB-1; Dako), dilution 1:100; and polyclonal antibodies anti CD117 (Dako), dilution 1:50; S100 (Dako), dilution 1:4,000 and PDGFRA (Cell Signaling, Danvers, MA, USA), dilution 1:200, following the manufacturer's instructions. In particular, PDGFRA was applied after antigen retrieval using heat-induced epitope retrieval (HIER) in a pressure cooker for $2 \mathrm{~min}$ in $5 \mathrm{mM}$ of EDTA buffer, $\mathrm{pH}$, after reaching the chamber pressure of 15-25 PSI and temperature of $120^{\circ} \mathrm{C}$.

PDGFRA immunostaining was independently evaluated by two pathologists (A.B. and A.F.), who had no knowledge of the tumor clinicopathological data and patient survival. Staining was scored as negative, weakly positive (Fig. 1A), moderately positive (Fig. 1B) and strongly positive (dotlike) (Fig. 1C).

For MIB-1 immunoreactivity, the absolute percentage of stained cells among at least 1,000 cells from the most active areas was recorded, and a cut-off value of $5 \%$ was used.

Molecular analysis. Genomic DNA was isolated from formalin-fixed paraffin-embedded tissue using xilene-ethanol for section deparaffinization and standard proteinase $\mathrm{K}$ digestion (overnight at $55^{\circ} \mathrm{C}$ ), followed by extraction using the phenol/chloroform method. The quality of the DNA extracted from the tumor tissue was tested by amplification of a 300-bp fragment of the human MHC class II (HLA-DRB) gene using the forward primer 5'-CCG GTC GAC TGT CCC CCC AGC ACG TTT C-3' and reverse primer 5'-GAA TTC TCG CCG CTG CAC TGT GAA GC-3. PCR amplification of exons 9, 11, 13 and 17 of the KIT gene $(15,29)$, and of exons 12 and 18 of the PDGFRA gene $(30,31)$, was carried out as previously described. PCR products were directly purified using paramagnetic bead technology Ampure (Agencourt Bioscience Corp., Beckman Coulter S.p.A, Milan, Italy) according to the manufacturer's protocol. Direct sequencing of the templates was carried out using the BigDye Terminator Cycle Sequencing Ready Reaction kit v1.1 (Applied Biosystems, Foster City, CA, USA) according to the manufacturer's protocol. Sequencing reactions were purified using CleanSeq magnetic beads (Agencourt Bioscience Corp., Beckman Coulter S.p.A) according to the manufacturer's protocol, and run on an ABI PRISM 310 automated capillary system (Applied Biosystems).

Statistical analysis. Independence between categorical variables and the type of KIT and PDGFRA mutation were estimated by the Yates' corrected $\chi^{2}$ test. Associations between tumor size, mitotic index and Ki67 score, and the type of KIT and PDGFRA mutation were assessed by one-way analysis of variance (ANOVA). Univariate DFS analysis was based on the Kaplan-Meier product-limit estimates of survival distribution (32), and differences between survival curves were tested using the generalized Wilcoxon test. All data were processed with BMDP selected programs (2D, 3D, 7D, 4F and 1L) (33).

\section{Results}

Among the 40 GISTs, $26(65 \%)$ carried KIT mutations and $14(35 \%)$ were KIT wild-type. There were 13 deletions, 6 substitutions (point mutations), 3 deletion-substitutions (deletion plus substitution), 3 duplications and 1 insertion. Twenty-five mutations occurred in exon 11 and 1 in exon 9. KIT mutations were grouped into two risk groups. The low-risk (LR) group included 12 cases with substitutions (6), deletion-substitutions (3) and duplications (3). The high-risk (HR) group included 14 cases with deletions (13) and an insertion (1).

PDGFRA mutations were found in 6 out of 40 cases $(15 \%)$; $34(85 \%)$ were wild-type for PDGFRA. There were 4 deletions and 2 substitutions (point mutations). Five mutations occurred in exon 18 and 1 in exon 12. Due to the small number of mutated cases, PDGFRA mutations were considered as a single group. Eight patients (20\%) were KIT and PDGFRA wild-type.

PDGFRA immunopositivity was found in 23 cases (57.5\%), 5 of which (12.5\%) showed strong immunoreactivity with prominent perinuclear 'dotlike' accentuation (Fig. 1C).

Association between type of KIT/PDGFRA mutation and clinicopathological variables. GISTs with PDGFRA mutations had a smaller size and a lower mitotic index (MI) and Ki67 score than tumors with KIT HR ( $\mathrm{p}=0.01)$.

At diagnosis, $83.3 \%$ of patients with PDGFRA mutations were asymptomatic, in contrast to only $25 \%$ of KIT/PDGFRA wild-type, $21.4 \%$ of KIT HR and $16.7 \%$ of KIT LR patients $(\mathrm{p}=0.02)$. Adjacent organ invasion at diagnosis was found in $35.7 \%$ of KIT HR and in $12.5 \%$ of KIT/PDGFRA wild-type cases, but not in PDGFRA mutated or KIT LR cases ( $\mathrm{p}=0.04)$. Distant metastasis occurred in $50 \%$ of $K I T$ HR and in $37.5 \%$ of KIT/PDGFRA wild-type cases, but in only $16.7 \%$ of PDGFRA mutated patients; no metastasis was observed in patients with $K I T$ LR $(\mathrm{p}=0.03)$. Additionally, relapse occurred in $50 \%$ of KIT/PDGFRA wild-type and in $35.7 \%$ of KIT HR cases, but 
A

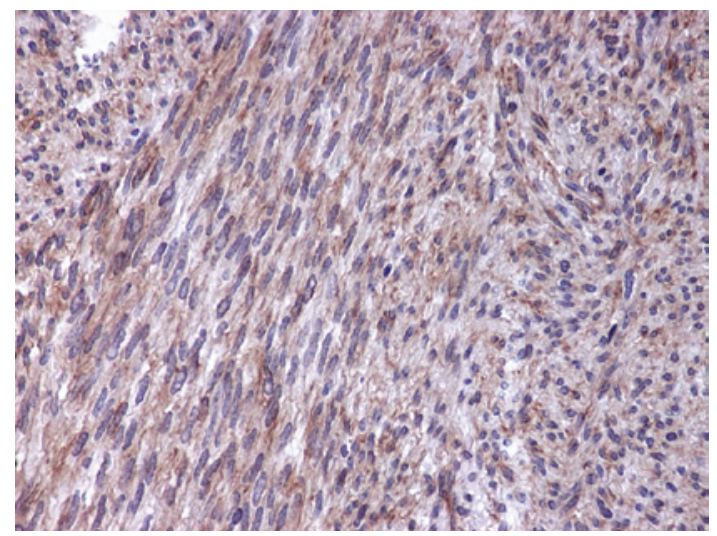

B

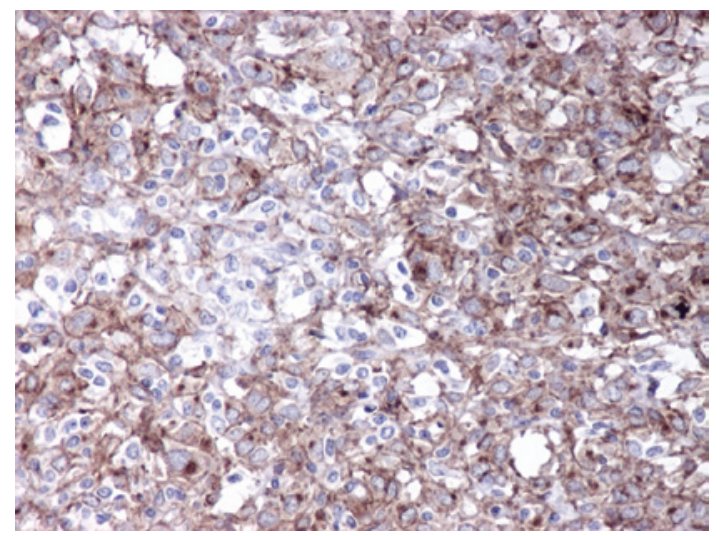

C

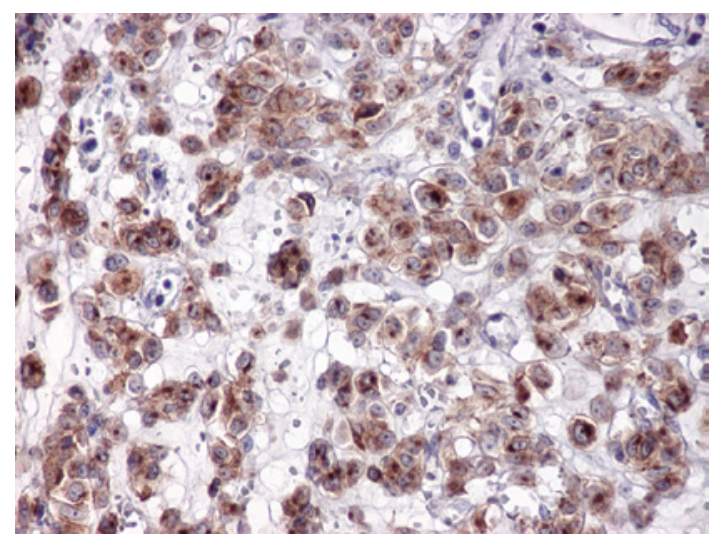

Figure 1. (A) Weak PDGFRA immunopositivity in spindle cell GIST. Most cells show faint diffuse cytoplasmic staining. (B) Moderately positive PDGFRA immunostaining in epithelioid GIST. A few cells show a perinuclear 'dotlike' accentuation (so-called Golgi pattern). (C) Strong PDGFRA immunopositivity with prominent 'dotlike' Golgi pattern in epithelioid GIST. Original magnification, $\mathrm{x} 400$.

in only $16.7 \%$ of PDGFRA mutated cases; no relapse occurred in patients with $K I T \mathrm{LR}(\mathrm{p}=0.05)$.

PDGFRA immunopositivity was found in all PDGFRA mutated cases, and in $62.5 \%$ of KIT/PDGFRA wild-type, $58.3 \%$ of KIT LR and only $35.7 \%$ of KIT HR cases. The difference between these results is of borderline significance $(\mathrm{p}=0.06)$. Notably, PDGFRA 'dotlike' immunopositivity (Fig. 1C) was found in 5 out of $6(83.3 \%)$ cases with PDGFRA mutations, but not in KIT HR, KIT LR or KIT/PDGFRA wildtype cases $(\mathrm{p}<0.0001)$. All 'dotlike' immunopositive cases were wild-type for KIT, 4 carried a PDGFRA deletion and 1 a PDGFRA substitution (point mutation).

The results are shown in Table I.
Correlation of type of KIT/PDGFRA mutation and PDGFRA immunostaining with disease-free survival. Out of 40 patients, $30(75 \%)$ were free of disease and $10(25 \%)$ relapsed. The 3- and 5-year DFS rates for the whole series were 81 and $58 \%$, respectively. At the 3-year follow-up, all the patients with PDGFRA mutations or KIT LR were free of disease, in contrast to only $87 \%$ of those with KIT/PDGFRA wild-type and $53 \%$ of those with KIT HR. The difference was only of borderline significance ( $\mathrm{p}=0.1$ ); however, the DFS of KIT LR patients was significantly longer than that of $K I T H R(p=0.05)$ or KIT/PDGFRA wild-type patients ( $\mathrm{p}=0.01)$ (Table II).

The 3- and 5-year DFS rates for patients with positive PDGFRA immunostaining were 95 and $72 \%$, respectively, but only 63 and $42 \%$, respectively, for those with negative PDGFRA immunostaining ( $\mathrm{p}=0.04)$ (Table II and Fig. 2).

\section{Discussion}

The results of the present study show that GISTs bearing KIT HR mutations were larger and had a higher MI than GISTs with KIT LR mutations. Also, $64.3 \%$ of KIT HR patients were at high risk of aggressive tumor behavior, as compared to $33.3 \%$ of those with KIT LR ( $\mathrm{p}=0.04) ; 35.7 \%$ presented with invasion into adjacent organs and relapsed, while no patients with KIT LR showed organ invasion or relapsed $(\mathrm{p}=0.03)$; distant metastases were found in $50 \%$ of KIT HR, but in no KIT LR cases ( $\mathrm{p}=0.003)$. Furthermore, only $53 \%$ of KIT HR patients were free of disease at the 5-year follow-up, in contrast to $100 \%$ of the KIT LR cases $(\mathrm{p}=0.05)$.

Our findings are in accordance with several studies reporting a poor prognosis for GISTs with KIT deletions (5-13) or insertions $(5,11,13)$, particularly those affecting the 557/558 codon. Indeed, our 2 cases with deletions in codons 557-558 showed metastatic disease at diagnosis and died at 6 and 11 months after surgery, respectively. However, our results are contradictory to a few studies reporting that KIT mutations are a ubiquitous feature of GISTs, either malignant or benign $(15,16)$, and that the type of KIT mutation has no prognostic value (17). Moreover, KIT duplications have been described in a few malignant advanced GISTs in series from imatinib trials $(18,19)$.

PDGFRA mutations were associated with rather indolent tumors; indeed, PDGFRA mutated GISTs had a smaller size and lower MI and Ki67 scores than GISTs with KIT HR mutations. Only 1 patient presented with symptoms (contrary to $80 \%$ of patients with KIT mutations; $\mathrm{p}=0.02$ ); none were at high risk of aggressive tumor behavior or experienced invasion into the adjacent organs; only 1 developed metastasis or relapsed; lastly, all were free of disease at the 40-month follow-up. Our results are in line with a few reports showing a favorable outcome for GISTs with PDGFRA mutations $(4,20)$. However, all cases with PDGFRA mutations were gastric GISTs, and it is known that gastric GISTs have a rather good prognosis. In our series, too, the median survival for the 27 gastric GISTs was 70.8 vs. 13.5 months for the 9 GISTs located in the small bowel and 4.8 months for those located in the large bowel $(\mathrm{p}=0.0004)$.

Notably, PDGFRA immunostaining tended to be associated with KIT or PDGFRA mutational status; indeed, positive PDGFRA immunostaining was present in all 
Table I. Association between type of KIT/PDGFRA mutation and clinicopathological variables.

\begin{tabular}{|c|c|c|c|c|c|}
\hline & $\begin{array}{l}\text { PDGFRA } \\
\text { deletions/ } \\
\text { substitutions } \\
\quad(\mathrm{n}=6)\end{array}$ & $\begin{array}{c}\text { KIT HR } \\
\text { deletions/ } \\
\text { insertion } \\
(\mathrm{n}=14)\end{array}$ & $\begin{array}{c}\text { KIT LR } \\
\text { substitutions/ } \\
\text { deletion-substitutions/ } \\
\text { duplications }(\mathrm{n}=12)\end{array}$ & $\begin{array}{c}\text { KIT/ } \\
\text { PDGFRA } \\
\text { wild-type } \\
(\mathrm{n}=8)\end{array}$ & \\
\hline Variable & No. $(\%)$ & No. $(\%)$ & No. $(\%)$ & No. $(\%)$ & \\
\hline \multicolumn{6}{|c|}{ Symptoms at diagnosis } \\
\hline Present & $1(16.7)$ & $11(78.6)$ & $10(83.3)$ & $6(75.0)$ & $\chi^{2}=9.73$ \\
\hline Absent & $5(83.3)$ & $3(21.4)$ & $2(16.7)$ & $2(25.0)$ & $\mathrm{p}=0.02$ \\
\hline \multicolumn{6}{|l|}{ Site } \\
\hline Stomach & $6(100)$ & $7(50.0)$ & $9(75.0)$ & 7 (87.5) & $\chi^{2}=6.77$ \\
\hline Other & $0 \quad(0)$ & $7(50.0)$ & $3(25.0)$ & $1(12.5)$ & $\mathrm{p}=0.07$ \\
\hline \multicolumn{6}{|l|}{ Histologic type } \\
\hline Spindle cell & $1(16.7)$ & $10(71.4)$ & $8(66.7)$ & $6(75.0)$ & $\chi^{2}=6.47$ \\
\hline Non-spindle cell & $5(83.3)$ & $4(28.6)$ & $4(33.3)$ & $2(25.0)$ & $\mathrm{p}=0.09$ \\
\hline \multicolumn{6}{|c|}{ Risk of aggressive behavior } \\
\hline Very low & $1(16.7)$ & $2(14.3)$ & $0 \quad(0)$ & $1(12.5)$ & $\chi^{2}=13.45$ \\
\hline Low & $3(50.0)$ & $0 \quad(0)$ & $4(33.3)$ & $1(12.5)$ & $\mathrm{p}=0.14$ \\
\hline Intermediate & $2(33.3)$ & $3(21.4)$ & $4(33.3)$ & $2(25.0)$ & \\
\hline High & $0 \quad(0)$ & $9(64.3)$ & $4(33.3)$ & $4(50.0)$ & \\
\hline \multicolumn{6}{|c|}{$\begin{array}{l}\text { Adjacent organ invasion } \\
\text { at diagnosis }\end{array}$} \\
\hline Present & $0 \quad(0)$ & $5(35.7)$ & $0 \quad(0)$ & $1(12.5)$ & $\chi^{2}=7.92$ \\
\hline Absent & $6(100)$ & $9(64.3)$ & $12(100)$ & $7(87.5)$ & $\mathrm{p}=0.04$ \\
\hline \multicolumn{6}{|l|}{ Distant metastasis } \\
\hline Present & $1(16.7)$ & $7(50.0)$ & $0 \quad(0)$ & $3(37.5)$ & $\chi^{2}=8.86$ \\
\hline Absent & $5(83.3)$ & $7(50.0)$ & $12(100)$ & $5(62.5)$ & $\mathrm{p}=0.03$ \\
\hline \multicolumn{6}{|l|}{ Relapse } \\
\hline Present & $1(16.7)$ & $5(35.7)$ & $0 \quad(0)$ & $4(50.0)$ & $\chi^{2}=7.74$ \\
\hline Absent & $5(83.3)$ & $9(64.3)$ & $12(100)$ & $4(50.0)$ & $\mathrm{p}=0.05$ \\
\hline \multicolumn{6}{|c|}{ PDGFRA immunostaining } \\
\hline Negative & $0 \quad(0)$ & $9(64.3)$ & $5(41.7)$ & $3(37.5)$ & $\chi^{2}=7.23$ \\
\hline Positive & $6(100)$ & $5(35.7)$ & $7(58.3)$ & $5(62.5)$ & $\mathrm{p}=0.06$ \\
\hline \multicolumn{6}{|l|}{$\begin{array}{l}\text { PDGFRA 'dotlike' } \\
\text { immunopositivity }\end{array}$} \\
\hline Present & $5(83.3)$ & $0 \quad(0)$ & $0 \quad(0)$ & $0 \quad(0)$ & $\chi^{2}=32.38$ \\
\hline Absent & $1(16.7)$ & $14(100)$ & $12(100)$ & $8(100)$ & $\mathrm{p}<0.0001$ \\
\hline Variable & Mean \pm SD & Mean \pm SD & Mean $\pm \mathrm{SD}$ & Mean \pm SD & \\
\hline Size $(\mathrm{cm})$ & $3.16 \pm 1.32^{\mathrm{a}}$ & $8.57 \pm 6.84^{b}$ & $6.41 \pm 3.05^{\mathrm{c}}$ & $4.62 \pm 2.26$ & $\mathrm{p}=0.08$ \\
\hline Mitotic index & $3.5 \pm 2.58^{\mathrm{d}}$ & $30.35 \pm 35.96^{\mathrm{e}}$ & $6.58 \pm 7.56^{\mathrm{f}}$ & $22.75 \pm 37.1$ & $\mathrm{p}=0.09$ \\
\hline Ki67 score & $3.0 \pm 1.67^{\mathrm{g}}$ & $9.5 \pm 7.9^{\mathrm{h}}$ & $5.25 \pm 6.73$ & $10.87 \pm 15.4$ & $\mathrm{p}=0.28$ \\
\hline
\end{tabular}

HR, high-risk group; LR, low-risk group. a vs. b, p=0.01; a vs. c, p=0.006; d vs. e, p=0.01; e vs. f, p=0.02; g vs. h, p=0.01 .

PDGFRA mutated cases, but in only $35.7 \%$ of KIT HR, $58.3 \%$ of KIT LR and $62.5 \%$ of KIT/PDGFRA wild-type cases. In particular, a strong perinuclear 'dotlike' staining (Golgi pattern) was found in $83.3 \%$ of PDGFRA mutated cases, but not in those with KIT mutations or in KIT/PDGFRA wild- type cases. Our findings confirm previous reports (24-26) and indicate that this peculiar PDGFRA-positive staining is a rather specific marker of PDGFRA mutations, and is typically absent in all KIT mutated cases. Further study is required to clarify the biological meaning of the 'dotlike' decoration. 
Table II. Correlation of type of KIT/PDGFRA mutation and PDGFRA immunostaining with disease-free survival in GISTs.

\begin{tabular}{|c|c|c|c|c|c|}
\hline Variable & No. & $\begin{array}{l}1 \text {-year DFS } \\
\text { rate }(\%)\end{array}$ & $\begin{array}{l}\text { 3-year DFS } \\
\text { rate }(\%)\end{array}$ & $\begin{array}{l}\text { 5-year DFS } \\
\text { rate }(\%)\end{array}$ & p-value \\
\hline Whole series & 40 & 92 & 81 & 58 & \\
\hline PDGFRA deletions/substitutions & 6 & 100 & 100 & 75 & \\
\hline $\begin{array}{l}\text { KIT LR (substitutions/deletion- } \\
\text { substitutions/duplications) }\end{array}$ & 12 & 100 & 100 & 100 & \\
\hline KIT HR (deletions/insertion) ${ }^{\mathrm{b}}$ & 14 & 85 & 53 & 53 & 0.10 \\
\hline$K I T / P D G F R A$ wild-type ${ }^{c}$ & 8 & 87 & 87 & 29 & \\
\hline \multicolumn{6}{|l|}{ PDGFRA immunostaining } \\
\hline Negative & 17 & 87 & 63 & 42 & \\
\hline Positive & 23 & 95 & 95 & 72 & 0.04 \\
\hline
\end{tabular}

DFS, disease-free survival; HR, high-risk group; LR, low-risk group. a vs. b, $p=0.05$; a vs. c, p=0 01

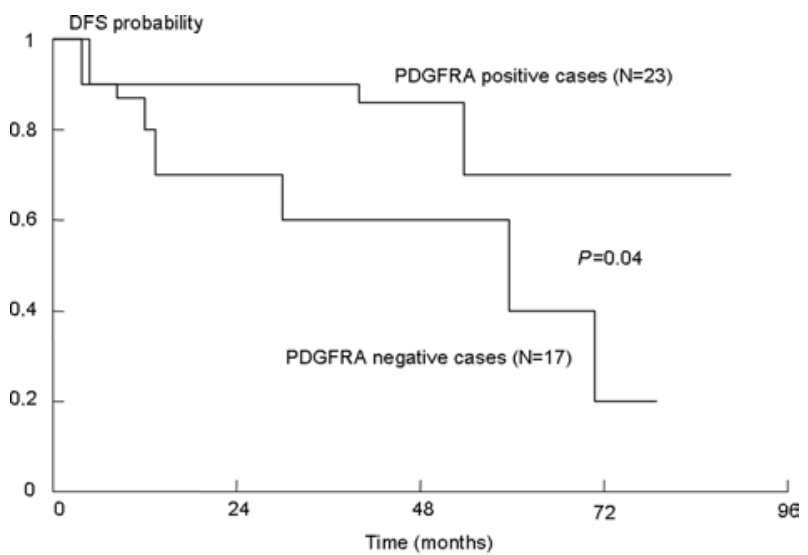

Figure 2. Actuarial probability of disease-free survival (DFS) for patients with GIST, categorized according to PDGFRA immunoreactivity.

The importance of PDGFRA immunostaining in GISTs is further supported by its prognostic value: 7 of 17 immunonegative cases $(41.2 \%)$ relapsed, while only 3 of 23 $(13 \%)$ immunopositive cases did $(\mathrm{p}=0.04)$. Moreover, at the 5-year follow-up, 72\% of PDGFRA immunopositive patients were free of disease, while only $42 \%$ of immunonegative patients were.

In conclusion, with the limitation due to the relatively small number of cases, our results confirm that the type of KIT mutation is associated with various biological and clinical behaviors of GISTs, and that PDGFRA mutations are associated with rather benign tumors. They also indicate that a strong PDGFRA immunopositivity reflects PDGFRA mutational status in GISTs and is associated with a good prognosis. Therefore, PDGFRA immunostaining should be a useful additional marker in the diagnostic and prognostic evaluation of GISTs.

\section{Acknowledgements}

This study was supported by grants from the Italian Ministero dell'Università e Ricerca Scientifica e Tecnologica (MURST).

\section{References}

1. Hirota S, Isozaki K, Moriyama Y, et al: Gain-of-function mutations of c-kit in human gastrointestinal stromal tumors. Science 279: 577-580, 1998.

2. Dei Tos AP: The reappraisal of gastrointestinal stromal tumors: from Stout to the KIT revolution. Virchows Arch 442: 421-428, 2003.

3. Heinrich MC, Corless CL, Duensing A, McGreevey L, Chen CJ, Joseph N, Singer S, Griffith DJ, Haley A, Town A, Demetri GD, Fletcher CD and Fletcher JA: PDGFRA activating mutations in gastrointestinal stromal tumors. Science 299: 708-710, 2003.

4. Lasota $\mathrm{J}$ and Miettinen M: KIT and PDGFRA mutations in gastrointestinal stromal tumors (GISTs). Semin Diagn Pathol 23: 91-102, 2006

5. Singer S, Rubin BP, Lux ML, Chen CJ, Demetri GD, Fletcher CD and Fletcher JA: Prognostic value of KIT mutation type, mitotic activity, and histologic subtype in gastrointestinal stromal tumors. J Clin Oncol 20: 3898-3905, 2002.

6. Wardelmann E, Losen I, Hans V, Neidt I, Speidel N, Bierhoff E, Heinicke T, Pietsch T, Büttner R and Merkelbach-Bruse S: Deletion of Trp-557 and Lys-558 in the juxtamembrane domain of the c-kit protooncogene is associated with metastatic behavior of gastrointestinal stromal tumors. Int J Cancer 106: 887-895, 2003.

7. Iesalnieks I, Rümmele P, Dietmaier W, Jantsch T, Zülke C, Schlitt HJ, Hofstädter F and Anthuber M: Factors associated with disease progression in patients with gastrointestinal stromal tumors in the pre-imatinib era. Am J Clin Pathol 24: 740-748, 2005.

8. Martín J, Poveda A, Llombart-Bosch A, Ramos R, López-Guerrero JA, García del Muro J, Maurel J, Calabuig S, Gutierrez A, González de Sande JL, Martínez J, De Juan A, Laínez N, Losa F, Alija V, Escudero P, Casado A, García P, Blanco R and Buesa JM; Spanish Group for Sarcoma Research: Deletions affecting codons 557-558 of the c-KIT gene indicate a poor prognosis in patients with completely resected gastrointestinal stromal tumors: a study by the Spanish Group for Sarcoma Research (GEIS). J Clin Oncol 23: 6190-6198, 2005.

9. Andersson J, Bümming $\mathrm{P}$, Meis-Kindblom JM, Sihto $\mathrm{H}$, Nupponen N, Joensuu H, Odén A, Gustavsson B, Kindblom LG and Nilsson B: Gastrointestinal stromal tumors with KIT exon 11 deletions are associated with poor prognosis. Gastroenterology 130: 1573-1581, 2006.

10. Braconi C, Bracci R, Bearzi I, Bianchi F, Costagliola A, Catalani R, Mandolesi A, Ranaldi R, Galizia E, Cascinu S, Rossi G, Giustini L, Latini L, Valeri N and Cellerino R: KIT and PDGFRalpha mutations in 104 patients with gastrointestinal stromal tumors (GISTs): a population-based study. Ann Oncol 19: 706-710, 2008.

11. DeMatteo RP, Gold JS, Saran L, Gönen M, Liau KH, Maki RG, Singer S, Besmer P, Brennan MF and Antonescu CR: Tumor mitotic rate, size, and location independently predict recurrence after resection of primary gastrointestinal stromal tumor (GIST). Cancer 112: 608-615, 2008. 
12. Lasota $\mathbf{J}$ and Miettinen M: Clinical significance of oncogenic KIT and PDGFRA mutations in gastrointestinal stromal tumours. Histopathology 53: 245-266, 2008.

13. Kontogianni-Katsarou K, Dimitriadis E, Lariou C, Kairi-Vassilatou E, Pandis N and Kondi-Paphiti A: KIT exon 11 codon 557/558 deletion/insertion mutations define a subset of gastrointestinal stromal tumors with malignant potential. World J Gastroenterol 14: 1891-1897, 2008

14. Lasota J, Dansonka-Mieszkowska A, Stachura T, Schneider-Stock R, Kallajoki M, Steigen SE, Sarlomo-Rikala M, Boltze C, Kordek R, Roessner A, Stachura J and Miettinen M: Gastrointestinal stromal tumors with internal tandem duplications in $3^{\prime}$ end of KIT juxtamembrane domain occur predominantly in stomach and generally seem to have a favorable course. Mod Pathol 16: 1257-1264, 2003.

15. Rubin BP, Singer S, Tsao C, Duensing A, Lux ML, Ruiz R, Hibbard MK, Chen CJ, Xiao S, Tuveson DA, Demetri GD, Fletcher CD and Fletcher JA: KIT activation is a ubiquitous feature of gastrointestinal stromal tumors. Cancer Res 61: 8118-8121, 2001.

16. Corless CL, McGreevey L, Haley A, Town A and Heinrich MC: KIT mutations are common in incidental gastrointestinal stromal tumors one centimeter or less in size. Am J Pathol 160: 1567-1572, 2002.

17. Kim TW, Lee H, Kang YK, Choe MS, Ryu MH, Chang HM, Kim JS, Yook JH, Kim BS and Lee JS: Prognostic significance of c-kit mutation in localized gastrointestinal stromal tumors. Clin Cancer Res 10: 3076-3081, 2004.

18. Antonescu CR, Besmer P, Guo T, Arkun K, Hom G, Koryotowski B, Leversha MA, Jeffrey PD, Desantis D, Singer S, Brennan MF, Maki RG and DeMatteo RP: Acquired resistance to imatinib in gastrointestinal stromal tumor occurs through secondary gene mutation. Clin Cancer Res 11: 4182-4190, 2005.

19. Debiec-Rychter M, Cools J, Dumez H, Sciot R, Stul M, Mentens N, Vranckx H, Wasag B, Prenen H, Roesel J, Hagemeijer A, van Oosterom A and Marynen P: Mechanisms of resistance to imatinib mesylate in gastrointestinal stromal tumors and activity of the PKC412 inhibitor against imatinibresistant mutants. Gastroenterology 128: 270-279, 2005.

20. Miettinen M and Lasota J: Gastrointestinal stromal tumors: pathology and prognosis at different sites. Semin Diagn Pathol 23: 70-83, 2006.

21. Hornick JL and Fletcher CD: The role of KIT in the management of patients with gastrointestinal stromal tumors. Hum Pathol 38 679-687, 2007

22. Rossi G, Valli R, Bertolini F, Marchioni A, Cavazza A, Mucciarini C, Migaldi M, Federico M, Trentini GP and Sgambato A: PDGFR expression in differential diagnosis between KIT-negative gastrointestinal stromal tumours and other primary soft-tissue tumours of the gastrointestinal tract. Histopathology 46: 522-531, 2005.
23. Lagonigro MS, Tamborini E, Negri T, Staurengo S, Dagrada GP, Miselli F, Gabanti E, Greco A, Casali PG, Carbone A, Pierotti MA and Pilotti S: PDGFRalpha, PDGFRbeta and KIT expression/activation in conventional chondrosarcoma. J Pathol 208: 615-623, 2006.

24. Pauls K, Merkelbach-Bruse S, Thal D, Büttner R and Wardelmann E: PDGFRalpha- and c-kit-mutated gastrointestinal stromal tumours (GISTs) are characterized by distinctive histological and immunohistochemical features. Histopathology 46: 166-175, 2005 .

25. Peterson MR, Piao Z, Weidner N and Yi ES: Strong PDGFRA positivity is seen in GISTs but not in other intra-abdominal mesenchymal tumors: immunohistochemical and mutational analyses. Appl Immunohistochem Mol Morphol 14: 390-396, 2006.

26. Miselli F, Millefanti C, Conca E, Negri T, Piacenza C, Pierotti MA, Tamborini E and Pilotti S: PDGFRA immunostaining can help in the diagnosis of gastrointestinal stromal tumors. Am J Surg Pathol 32: 738-743, 2008.

27. Blay J-Y and Bonvalot S: Consensus meeting for the management of gastrointestinal stromal tumors. Ann Oncol 16: 566-578, 2005.

28. Fletcher CD, Berman JJ, Corless C, Gorstein F, Lasota J, Longley BJ, Miettinen M, O'Leary TJ, Remotti H, Rubin BP, Shmookler B, Sobin LH and Weiss SW: Diagnosis of gastrointestinal stromal tumors: a consensus approach. Hum Pathol 33: 459-465, 2002.

29. Lasota J, Wozniak A, Sarlomo-Rikala M, Rys J, Kordek R, Nassar A, Sobin LH and Miettinen M: Mutations in exons 9 and 13 of KIT gene are rare events in gastrointestinal stromal tumors. A study of 200 cases. Am J Pathol 157: 1091-1095, 2000.

30. Sakurai S, Hasegawa T, Sakuma Y, Takazawa Y, Motegi A, Nakajima T, Saito K, Fukayama M and Shimoda T: Myxoid epithelioid gastrointestinal stromal tumor (GIST) with mast cell infiltrations: a subtype of GIST with mutations of platelet-derived growth factor receptor alpha gene. Hum Pathol 35: 1223-1230, 2004.

31. Sihto H, Salormo-Rikala M, Tynninen O, Tanner M, Andersson LC, Franssila K, Nupponen NN and Joensuu H: KIT and platelet-derived growth factor receptor alpha tyrosine kinase gene mutations and KIT amplifications in human solid tumors. J Clin Oncol 23: 49-57, 2005.

32. Kaplan EL and Meier P: Non parametric estimation for incomplete observations. J Am Stat Assoc 53: 457-481, 1958.

33. Dixon WJ, Brown MG, Engelman L, Hill MA and Jennrich RI: BMPD Statistical Software Manual. University of California Press, Berkeley, 1990. 